\title{
HRM and innovation: looking across levels.
}

\author{
Accepted for publication in Human Resource Management Journal
}

Helen Shipton, Professor of International HRM, Nottingham Trent University, Nottingham Business School, helen.shipton@ntu.ac.uk

Pawan Budhwar, Professor of International HRM, Aston University, p.s.budhwar@aston.ac.uk

Paul Sparrow, Professor of International HRM, Centre for Performance-led HR, Lancaster University Management

School,p.sparrow@lancaster.ac.uk

Alan Brown, Professorial Fellow, Institute for Employment Research, University of Warwick, Alan.Brown@warwick.ac.uk

\begin{abstract}
Studies are starting to explore the role of HRM in fostering organizational innovation but empirical evidence remains contradictory and theory fragmented. This is partly because extant literature by and large adopts a unitary level of analysis, rather than reflecting on the multi-level demands that innovation presents. Building on an emergent literature focused on HRM's role in shaping innovation, we shed light on the question of whether, and how, HRM might influence employees' innovative behaviours in the direction of strategically important goals. Drawing upon institutional theory, our contributions are three-fold: to bring out the effect of two discrete HRM configurations- one underpinned by a control and the other by an entrepreneurial ethos, on attitudes and behaviours at the individual level; to reflect the way in which employee innovative behaviours arising from these HRM configurations coalesce to shape higher-level phenomena, such as organizational-level innovation; and to bring out two distinct patterns of bottom-up emergence, one driven primarily by composition and the other by both composition and compilation.
\end{abstract}




\section{INTRODUCTION}

One of the central challenges facing organizations given global uncertainty, escalated technological change and ever-growing consumer expectations is enhancing, renewing and revitalizing existing work systems, services and products. It has been argued that organizations exhibiting innovation, rather than remaining committed to what worked in the past, are more likely to thrive in challenging times (Shalley, Gilson and Blum, 2009). Yet innovation presents challenges for organizations, and moving away from accepted ways of working into new domains is not straightforward, especially given peoples' commitment to what worked well in the past (Unsworth and Clegg, 2010). It has been argued that isomorphic pressures reinforce rigidity in line with what is accepted and legitimate rather than opening the prospect for critical reflection, novelty and value-added change (Di Maggio and Powell, 1983).

Although traditionally innovation has been viewed as in the hands of scientific or technological specialists, there is now recognition that organizations have the potential to draw on the insights, abilities and motivations of employees across levels and functional areas. This raises the prospect for improvements that may be more incremental than radical but nonetheless add strategic value. It also points to the importance of supporting others in their quest to enhance organizational functioning, suggesting that innovation arises in part from bottom-up interactive activities across employee groups as well as by endeavours of scientific experts or business leaders. Implicit in this view is that human resource management (HRM) influences the propensity of employees to work in this way. With significant exceptions (Collins and Smith, 2006) studies have adopted a unitary level of analysis, investigating the effect of a set of organizational-level predictors on organizational outcomes. Yet according to Gupta et al. (2007) innovation is inherently multi-level, since it represents change in one entity in response to a wider context. One danger implicit in adopting a unitary frame of reference is misattributing causality to the variables in question when some deeper factor is at play (Carpenter, Li and Jiang, 2012).

In this paper we build on the emergent literature on HRM's role in shaping innovation in order to shed light on how HRM influences employees' innovative behaviours towards strategically important goals. Drawing on institutional theory (Di Maggio and Powell, 1983), our explanation highlights two discrete HRM configurations (see Figure 1), underpinned by principles of isomorphism. We describe the first configuration as 'control-oriented HRM' and the second as 'entrepreneurial HRM', which involves exploring options for challenging the institutional 
parameters that may inhibit innovation. This latter configuration is derived, but distinct, from the contingency perspectives in HRM (Chadwick and Dabu, 2009; Kang, Morris and Snell, 2007). We explain how employee innovative behaviours can arise from these different HRM configurations and coalesce to shape organizational-level innovation. These cross-level innovation processes bring out two distinct patterns of bottom-up emergence, one primarily driven by 'composition' and the other by both 'composition' and 'compilation'.

Although contingency perspectives have proposed contrasting configurations of HRM practices depending upon internal and external fit (Schuler and Jackson, 1987), they understate the role of institutional isomorphism (Di Maggio and Powell, 1983) in consciously or unconsciously shaping both strategic leadership or employee perceptions about what actions are apposite within a given context. Yet research in the psychology of strategic management reveals that the problem of organizational alignment, and the ability to pursue control-based innovation, has much to do with the subsequent decision making quality (Hodgkinson and Healey, 2008).

We argue that the underlying premise for control-oriented HRM is primarily composition (Kozlowski and Klein, 2000). Employees respond in a similar way to the environment to which they are exposed and the emergent phenomenon at the level of the collective is identical to its constituent elements. In contrast, entrepreneurial HRM is premised by the notion that emergence compiles from the bottom up (Kozlowsi and Klein, 2000). Although composition has a role, this perspective suggests that individual attitudes and behaviours configure to form idiosyncratic patterns, which compile in unique ways to shape emergent phenomena (such as innovation). Taking account of the bottom-up, emergent properties as well as top-down effects extends and enriches thinking by providing a comprehensive picture of the complex dynamics that innovation entails. 


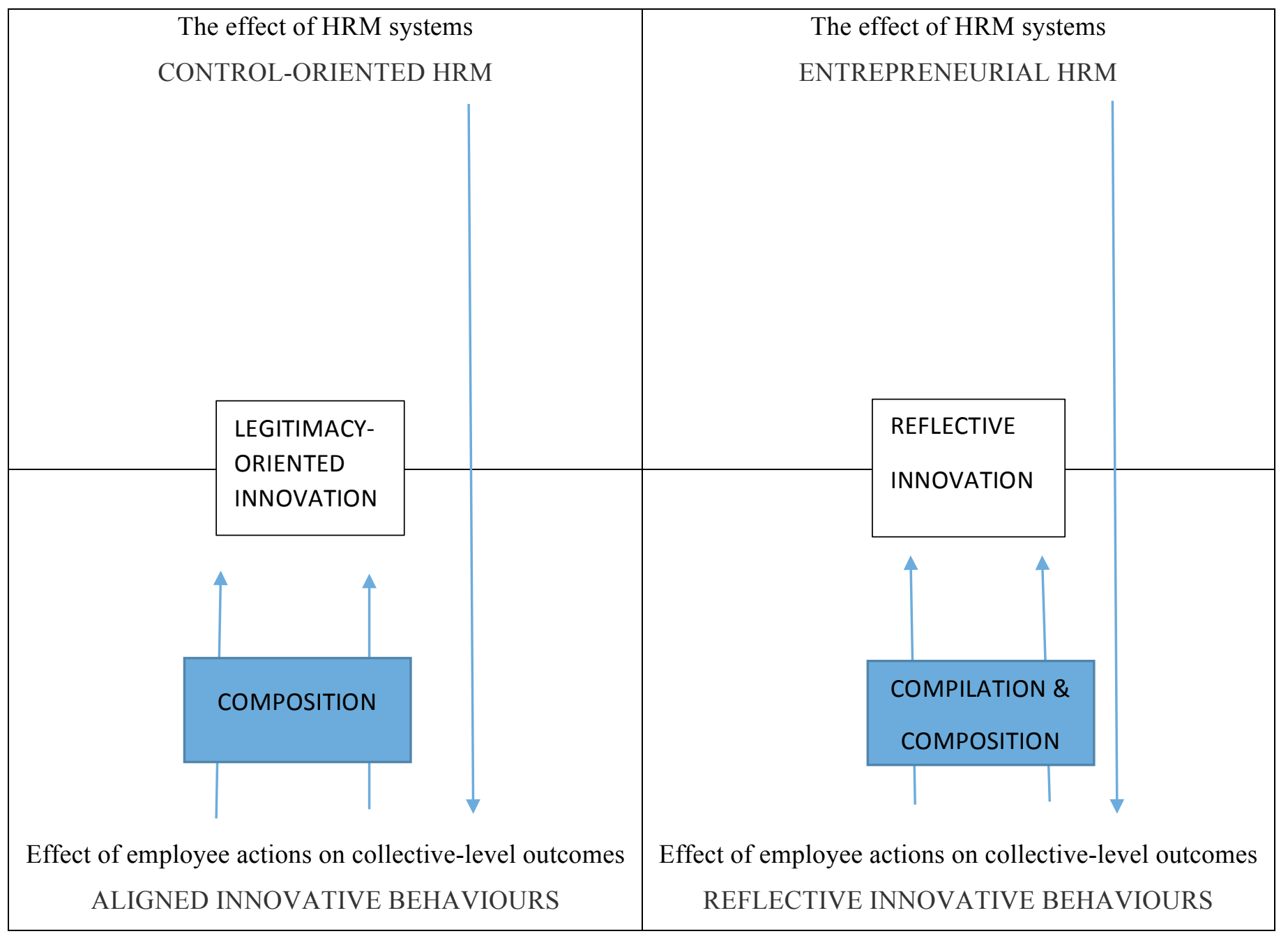

\section{THEORETICAL FRAMEWORK}

\section{Creativity, innovative behaviours and innovation}

The literatures focused on creativity, innovative behaviours and innovation are vast and it is not our intention to undertake a comprehensive review (Anderson, Potocnik and Zhou, 2014), but rather to draw out pertinent themes. While creativity is argued to be primarily an individual attribute encompassing a series of stages (e.g. problem definition, preparation/ information gathering, idea generation and idea evaluation) (Montag, Maertz and Baer, 2012), innovation is generally viewed as an organization-wide activity that represents the (collective-level) outcome of creative endeavour. 
Creativity is traditionally viewed as the 'front end' of the innovation process (West and Farr, 1990). For a discussion on dimensions of creativity, and how they result in 'innovative behaviour' see Sullivan and Ford (2010), Piaget (1970) and (Scott and Bruce, 1994). We do not compartmentalize creativity as distinct from innovative behaviours, but rather see innovative behaviours as a set of actions with creativity at their heart. We therefore use the terms creative behaviour and innovative behaviour synonymously throughout the paper.

Montag et al. (2012) highlight a distinction between creative/ innovative behaviours and the outcomes that flow from these behaviours. This perspective separates two factors arising at different levels of analysis: individual behaviours and collective outcomes arising from those behaviours. According to our argument, innovation is the collective manifestation (in concrete form) of individual-level behaviours that are both original (novel for the context) and feasible (have the potential to be enacted). Thus, innovation represents change that is intentional, novel and valuable within the context where it occurs (West and Farr 1990) arising from the individual creative and innovative actions. An innovation might be limited in scope (e.g. a team setting aside time for regular reflection) or radical (the team implementing a new system of peer review that is taken up by the whole organization). We also suggest that an innovation may be more or less aligned with the institutional parameters that frame and underpin organizational endeavour (Di Maggio and Powell, 1983).

Employees make careful assessments of the environment before committing themselves to extra-role actions that could entail negative social evaluations (Bednall, Sanders and Runhaar, 2014; Yuan and Woodman, 2010). In this paper our focus is the innovative behaviours and creativity that arise without being overtly required (Montag et al., 2012). Investigating the antecedents of creative/ innovative behaviours that are not overtly expected casts light on the more spontaneous aspects of employee behaviour that may diminish without the appropriate environment being in place. We argue that contexts may not just suppress but also skew such behaviours. For example, in constrained environments where legitimacy considerations are paramount employees may engage in innovative actions that are prescribed or aligned with what will be recognized and rewarded. New ideas may be put forward because other comparable organizations are doing likewise, rather than because such suggestions meet a clearly defined need.

\section{Institutional theory, innovative behaviours and HRM}

Institutional theory (Scott, 2004) provides a useful set of explanations for why firms (and actors within them) do not always behave in a rational way, striving for legitimacy as well as performance outcomes defined in an economic 
sense. Institutional legitimacy is defined as 'a generalised perception or assumption that the actions of an entity are desirable, proper, or appropriate within some socially constructed system of norms, values, beliefs and definitions' (Suchman, 1995, p. 574). Cognitive processes create taken-for-granted structures that establish legitimacy around key aspects of organizational functioning (DiMaggio and Powell, 1983). Hence organizations become increasingly similar, despite the efforts of rational actors to change them. This process of homogenisation has been described as isomorphism (see Dimaggio and Powell, 1983; Paauwe and Boselie, 2003 for coercive, normative mimetic types of isomorphism), a constraining force that brings organizations together within an institutional field.

There have been calls by scholars to focus on the micro rather than the macro implications of institutionalism because institutional logics 'have a perceptual component that operates cognitively at the level of individuals (Suddaby, 2014, p. 17). Boon, Paauwe, Boselie and Den Hartog (2009) show that mangers have choices in the way in which they respond to institutional contexts, through embracing HRM systems that either conform or challenge.

\section{HRM, performance and innovation}

Strategic HRM research has demonstrated that bundles of HR practices, labelled high-performance, high involvement or high commitment, are associated with a range of indicators, both at unit level (e.g. productivity) as well as financial outcomes (Patel, Messersmith, and Lepak, 2013). Although early work on HRM/performance relationships adopted a unitary level of analysis, investigating the extent to which management perceptions of HRM are associated with outcomes conceptualized at the firm level, more recently scholars have started to take into account causal factors at different levels of analysis. For example Kaše, Paauwe and Batistič's (2014) examination of the intellectual structure of the HRM-performance literature using cocitation analysis noted the need for multi-level theoretical models. Also, a growing literature brings employees to the forefront and raises questions not only about how top-down perspectives influence stakeholders lower in the organizational hierarchy (e.g., Jiang and Liu, 2015) but also what is the process whereby bottom-up effects are translated into performance outcomes at a higher level of analysis (Alfes, Shantz, Truss, and Soane, 2013).

The multi-level perspectives have then brought out the distinct effect of configurations of HR systems on specific individual outcomes. Delery and Shaw (2001) proposed that staffing, training and compensation primarily influence employee knowledge, skills and motivation but not employees' perceptions of empowerment. Furthermore, certain categories of HR systems (e.g. training) are appropriate for enhancing skills, while others (e.g. reward and 
recognition, appraisal) promote motivation (Katou and Budhwar, 2015). Whereas Chadwick and Dabu (2009) allude to the role of employee proactivity and freewill, underpinned by empowering work structures, in fostering innovationoriented performance outcomes.

From literature focused on HRM and innovation we draw out four underlying themes: HRM systems/practices; potential mediators and moderators (Patel et al., 2013); levels of analysis (where the focus is individual behaviours, or where outcomes are captured at a higher level than the individual) (Montag et al., 2012); and whether innovative outcomes are expected, or alternatively not a requirement of the job. We exemplify key trends rather than reviewing every paper.

\section{HRM systems/practices}

Scholars investigating the link between HRM and innovation have followed a similar line to that pursued by SHRM researchers, i.e. identifying clusters of practices linked to performance outcomes including innovation. Prieto, Perez-Santana and Sierra (2010) draw on what they describe as 'high involvement' HR practices, drawing on three factors to represent ability-enhancing, motivation enhancing and opportunity-enhancing domains (building on Appelbaum's AMO framework). Surprisingly, motivation-enhancing HR practices did not yield a statistical relationship with innovative work behavior. Whereas the study by Jimenez-Jimenez and Sanz-Valle (2008) revealed a positive and significant relationship between HR practices (flexible job design and empowerment, team working and skill-oriented staffing) and product, process and administrative innovation.

Nevertheless there remain underlying tensions in the literature. For example, Zhao and Chadwick (2014) found that a measure labelled - 'New Product Development Motivation' (our italics), capturing employees' willingness to work collaboratively and take risks in developing new ideas, was more strongly associated with incremental innovation than that capturing employee skills and capability. Similarly, Beugelskdijk's (2008) research focusing on creativity-based HRM practices reported mixed results where incremental innovation was associated positively and significantly with most of the HR variables but performance-based pay, where combined with flexible hours or task rotation was significantly and negatively linked with radical innovation.

Such findings indicate that the optimum HRM configuration for innovative behaviours may be subtly different relative to other outcomes such as work performance. Innovative behaviours based on merit or efficiency considerations (Yuan and Woodman, 2010) may arise where individuals become aware of isomorphic pressures and 
adopt a more critical and reflective stance. This might entail exposure to alternative paradigms, thereby allowing employees to question and critique cognitive channels that have evolved over time. This line of reasoning suggests that opportunity dimension of the AMO framework might be central for innovation, by presenting alternatives to current practice, instead of a continuation of thought and action in a prescribed direction.

\section{Mediators and moderators}

Researchers investigating HRM and innovation have generally regarded knowledge exchange as a mediator of HPWS-innovation relationships (e.g. Chen and Huang, 2011; Collins and Smith, 2006). Recent study by Fu et al. (2015) examining the effect of high performance HRM practices on organizational innovation, reveal full mediation by employee innovative behaviours. Turning to moderation, Chang et al. (2014) show that high performance work practices are conducive to employee creativity where team cohesion and task complexity are high. Research by Sanders et al. (2015) uncovers the contingent effect of national culture as well as HRM implementation on the HPWPinnovative behaviour relationship. Employees located in countries emphasising toward uncertainty avoidance and collectivism orientations are relatively less innovative, suggesting the effect of context. Similarly, other variables such as focus on R\&D teams (e.g. Chang et al., 2014) and how innovation is measured reveal the significance of context and the challenges it create to compare the effects of mediation and moderation across studies (a point further discussed below).

\section{Behaviours/ Outcomes}

Studies focus on two categories of behaviours/outcomes - organizational and individual level. Dorenbosch, van Engen and Verhagen (2005) show that employees experiencing jobs with variety and scope for learning are more innovative than where the converse is true. Rarely (e.g. Fu et al., 2015) an assumed link between employee innovative behaviours and organizational innovation has been empirically verified. For examples of research examining organizational-level outcomes see Cabello-Medina, Lopez-Cabrales and Valle-Cabrera (2011) and Zhao and Chadwick (2014). There are thus significant differences in the literature about how to capture innovation measured at the organizational level. Given that a longstanding discourse within innovation literatures has alluded to the role of fad and fashion in shaping innovation (e.g. Wolfe, 1994) it is at least possible that some innovations are more 'economically rational' (Di Maggio and Powell, 1983) than others. Also, it could be that in closely prescribed environments, there is less scope or opportunity for employees to look beyond stipulated parameters. This might mean that any innovation that does occur is aligned with predominant institutional logics rather than assessed in a 
more critically detached sense (Hodgkinson and Healey, 2008). Drawing insights from Dorenbosch et al. (2005) and Shipton et al. (2006), we suggest that employees who are exposed to new experiences and perspectives and encouraged to bring out their divergent perspectives may to some extent offset the challenge that these institutional pressures present.

Certain configurations of HRM, such as those allowing less scope for questioning and challenge at lower levels of the organizational hierarchy, may inspire bottom-up emergence that is compositional, mainly shaped by isomorphic pressures. Other forms may open opportunities for employees to move beyond accepted wisdom to bring unique knowledge, experience and extended networks to inform any outcomes that subsequently arise at the level of the organization. To the extent that team leaders, line managers and senior parties are open to perspectives that diverge from institutionally-driven parameters, bottom-up emergence may occur through compilation.

Innovative behaviours/ creativity: expected v. unexpected

We have noted above that a significant proportion of research in this area has been carried out where employees are expected to be innovative, in that they operate within organizations, which are strategically oriented to this end (Chang et al., 2014; Collins and Smith, 2006). Other research is guided by the premise that innovations flow from employees at all levels of the business, yet omits to capture the extent to which creativity or innovation is required to a greater or lesser extent for some rather than others (Beugelskdjk, 2008; Shipton et al., 2006). Creative people are generally highly intrinsically motivated, more highly trained and inclined to work autonomously than those who are not expressly conditioned to work in this way (Montag et al., 2012).

\section{Summary}

HRM research has generally focused on top-down models, arguing that HRM influences employee workrelated attitudes through shaping organizational climate (Takeuchi, Lepak, Wang and Takeuchi, 2007) or through creating an environment perceived by employees to be psychological empowering (Jiang et al., 2013). Bottom-up perspectives are less researched, although SHRM research reveals that aggregated employee attitudes induce employee citizenship behaviours, which are in turn associated with customer satisfaction (Nishii et al., 2008), while aggregate service performance lead to unit-level market performance, taking into account individuals' perceptions of the high performance work practices (Alfes et al., 2013).

Where the focus is innovation, a number of important questions remain unanswered. As Jiang et al. (2013) point out, although research aligned with the AMO framework has deepened understanding on the first two 
dimensions, little research has yet explored the notion of 'opportunity' (Takeuchi et al., 2007). Considering that 'opportunity' (e.g. through involvement, new tasks) exposes employees to the new perspectives and experiences that may open new cognitive channels (McGrath, 2001), this is an important omission. There is also a lack of attention to the way in which bottom-up emergence occurs. The above perspectives are suggestive of emergence through composition (rather than compilation) since they are derived from assessments of relative within-group variance (James, Demaree and Wolfe, 1984). Although Kozlowski and Klein (2000) distinguish between two discrete patterns of emergence- composition and compilation, research to date has (implicitly) adopted a compositional framing and compilation has been more or less left out of the story.

Insights from institutional theory reveal that spontaneous actions, which do not fit into prescribed patterns are likely to be suppressed given a context where isomorphic pressures are dominant (Di Maggio and Powell, 1983). It could be that these pressures impact disproportionately on those for whom creativity and innovation is not overtly required. Creative professionals are probably less influenced by their environments than those for whom creativity and innovation is an extra-role behaviour (Montag et al., 2012).

\section{THE MODEL -A MULTI-LEVEL FRAMEWORK OF HRM AND INNOVATION}

In order to help address the above-identified gaps, and building upon the recent work on HRM-innovation linkage, we now present our model (see Figure 1). This model comprises four quadrants, each of which suggests different configurations of HRM. The top two quadrants highlight the top-down effects of contrasting HRM systems on employee innovative behaviours. The bottom two quadrants bring out the bottom-up effects of employee actions on collective-level outcomes, defined in terms of 'aligned' versus 'reflective' innovation. The first axis differentiates the effect of HRM systems that are control-oriented as opposed to those based on open networks and structures that foster informal interconnections within and across boundaries and hierarchies (Kang et al., 2007). The second axis examines bottom-up effects. Figure 1 highlights two patterns of bottom-up emergence. The first occurs through a process of composition (Kozlowski and Klein, 2000) in reaction to control-oriented HRM, where isomorphic pressures are strong and influence patterns of interaction to induce a degree of homogeneity that constrains patterns of action (Di Maggio and Powell, 1983).

The second pattern occurs through composition and compilation (Fulmer and Ostroff, 2015) in response to entrepreneurial HRM. Composition can occur through employees' thoughts and actions emerging in response to 
shared perceptions of the wider context as a result of institutional pressures, but compilation (the bringing together of diverse abilities, perspectives and insights into a coherent whole) has primacy within this quadrant. Compilation requires reconciliation of diverse perspectives and suggests a (relatively) reflective stance (Scott, 2004). We now explain each part of the model in detail.

\section{Control-oriented HRM: Top down effects}

HRM practices within this quadrant are selected according to whether they enable alignment in response to normative, coercive and mimetic pressures (Di Maggio and Powell, 1983). As Paauwe and Boselie (2003) point out, this orientation is not necessarily to the detriment of resource-based perspectives (Barney, 1991), since firms may build unique, valuable and difficult-to-imitate capabilities that facilitate careful positioning relative to the wider context. To this extent, HRM configurations for this quadrant are not dissimilar from HR archetypes contingent upon an organization's strategic remit (Schuler and Jackson, 1987). The HRM configuration associated with this paradigm is however suggestive of conformity and convergence rather than deeper questioning and reflection (Boon et al., 2013). Here we would expect to find HRM practices that promote employee alignment with the institutional context and emphasise consensus. For example, through performance appraisal employees would be expected to achieve specified targets that are in line with what is perceived appropriate given isomorphic pressures and constraints (Di Maggio and Powell, 1983).

Given that employees are not expected to critically challenge beyond legitimized parameters probably this HRM configuration would fall short of the 'best practice' model by giving less emphasis to the job design and empowerment components that have been described in SHRM literatures (e.g. Collins and Smith, 2006). Especially when institutional pressures are suggestive of non-negotiable parameters guiding employee action it is unlikely to be viewed as helpful for the achievement of strategic goals if employees are given a lot of latitude. They may however be expected to behave innovatively to the extent that ideas and actions are aligned with pre-determined parameters.

Several organizational forms reflect the need for what we define as top down control-based HRM. For example, the internal professional services model (Anand, Gardner \& Morris, 2007) assumes that control is possible through skill sets associated with the management of innovation (such as project management, corporate performance management setting) made available and delivered via a centre of excellence and business consulting unit with central

powers of control over the introduction of innovations. Similarly, using external venture capital models and acquiring and then internalising the running of entrepreneurial start-up operations (Robeson and O'Connor, 2013) assumes that 
the organization can segment the innovation process from the rest of the organization by setting up proto-governance structures with "incomplete" contracts, and meld incentive arrangements for newly internalised lead employees (agents) in ways that protect the interests of the corporate owners (principals). Accordingly, those who are 'creative' are separated from the rest of the workforce who have a more modest remit to align their behaviours as required.

In sum, control-oriented HRM is characterised by less scope for employees to engage in creative endeavour and relatively unquestioning adherence to what is expected and legitimate (Boon et al., 2013). Hence, employees will be on the whole less innovative. Any innovative behaviour that does arise will be skewed in the direction of what is legitimate and acceptable according to different isomorphic pressures (Di Maggio and Powell, 1983). This line of thinking leads to the following proposition:

Research Proposition 1: Control-oriented HRM fosters employee innovative behaviours that are aligned with institutional norms, values and expectations

\section{Control-oriented HRM: Bottom-up effects}

In this quadrant we consider the way in which emergent, bottom-up processes coalesce at the higher level through composition, and what this means for HRM and innovation. Aligned innovation, emerging from bottom-up compositional processes, addresses priorities emphasised in environments where institutional pressures are strong. Often flowing from mimetic pressures, such innovations might fail to yield the outcomes envisaged because they are instigated in response to perceived pressures rather than arising from compelling business needs. Coercive pressures could similarly lead to outcomes that are counter-productive, such as a new policy on the employment of minority groups above and beyond what the law requires, in a way that alienates mainstream employee groups. Normative demands might entail tying promotion opportunities to specialist professional groups without considering whether others outside pre-defined parameters might perform equally well, or better. Developments are potentially dysfunctional to the extent that they flow from unquestioning endorsement of the parameters set out by the institutional environment.

Bottom-up emergence that occurs through composition is likely to foster this type of innovation. Radical or more questioning/reflective insights may be driven out by isomorphic constraints. Individuals are encouraged to exhibit similar behaviours. Pressures to conform might induce core rigidities or competency traps (Benner and 
Tushman, 2003) that prevent organizations looking outside for radical alternatives to position them more strongly in the market place given changing external dynamics. Thus, isomorphic pressures may give rise to collective-level outcomes that meet legitimacy and conformity requirements rather than efficiency goals (Yuan and Woodman, 2010), leading us to assert the following:

Research Proposition 2: Aligned innovative behaviours emerge through composition to engender aligned innovation

\section{Entrepreneurial HRM: Top-down effects}

In this quadrant, a contingency perspective referencing a set of practices that are conducive to exploratory learning and innovation (Kang et al., 2007), is useful and we add to it in two ways. First, entrepreneurial HRM promotes innovation where it facilitates compilation as well as composition (discussed under quadrant four). Secondly, entrepreneurial HRM is intended to bring out employee actions that critically reflect upon the dominant institutional parameters that may otherwise be unacknowledged. Thus, it is characterised by HPWPs that offer opportunities for employees to be exposed to new experiences, through job secondments, projects, promoting links with end-users, action learning sets and so on. It attempts to foster active awareness and critique of institutional parameters that might otherwise emphasise conformity (Boon et al., 2013).

Rather than discouraging employees from articulating their interpretations and ideas, practices in this quadrant instead actively solicit, encourage and reward discretionary effort, including recognizing and rewarding creative and innovative outcomes. Training here is less important than in the first quadrant (control-oriented HRM), since the focus is on ideas that may run counter to prevailing institutional logics. At a premium are managerial practices that foster strong interpersonal skills, enabling the generation and exploitation of knowledge held by communities of actors both with the firm and across organizational hierarchies.

Although HRM has not generally emphasised the development of political skills in order to appreciate the limitations presented by institutional isomorphism, leaders and employees more generally may need help and support in this area. Individuals and teams require highly developed interpersonal and persuasive skills, and the ability to position ideas within the institutional context such that they garner support rather than alienation (Rao and Giorgi, 2006). Mentoring is likely to be at a premium for entrepreneurial HRM, since this way of working allows individuals to absorb how more experienced members both consciously and unconsciously deal with political agendas. Coaching 
too, where focused on persuasion and negotiation, can play an important part in helping employees to position their ideas, as can team learning, peer support and insightful forms of performance review.

This HRM configuration is further suggestive of bringing together two modes of innovation: the science, technology, and innovation (STI) mode (where creativity and innovation is actively expected and anticipated) and the doing, using and interacting (DUI) mode, which emphasises participation, and collective learning and development (Jensen, Johnson, Lorenz and Lundvall, 2007). Thus expertise is seen as widely spread and distributed within organisations, rather than just residing in individuals (Brown and Duguid, 1991).

A series of capabilities are necessary to support this more entrepreneurial HRM, such as continuous monitoring of resources and competence gaps, the development of specialised management and technical competences and their distribution across many actors within collaborative networks, a capacity for the organization to transform its underlying structures, creating cultures that learn, being part of a wider innovation eco-system, and establishing learning communities that have common purpose and common incentives for successful knowledge production (Chesbrough, 2003). Distributed and open innovation settings are also important, requiring forms of HRM that enable gains through mutual knowledge, roles, structures and dynamics of self-organising ideation communities, and policies, practices and organisational climate to increase employees' commitment to knowledge sharing (Florén, Rundquist, Schuler and Bondarouk, 2014). All these factors influence the behaviours that individuals exhibit such that they are more detached and critical relative to institutional parameters. Accordingly, we propose that:

Research Proposition 3: Entrepreneurial HRM promotes reflective innovative behaviours

\section{Entrepreneurial HRM: Bottom-up effects}

We suggest that for this quadrant innovative behaviours coalesce through two complementary processes: composition (a pattern that facilitates bottom-up emergence for aligned innovation), and compilation (a pattern of bottom-up emergence that reconciles divergent perspectives into a coherent whole). Understanding how compilation occurs to influence outcomes at the collective level is still work in progress (Fulmer and Ostroff, 2015). Here we only lay out lines of inquiry, rather than offering definitive conclusions.

Bottom-up emergence through composition occurs as a climate for innovation arises where there is a collective sense that the environment offers support for risk-taking and experimentation and encourages collaboration and 
knowledge sharing (Scott and Bruce, 1994). Individuals are recognized and rewarded for their ideas and encouraged by HRM practices that signal that innovation is important and valued (Bowen and Ostroff, 2004). Interaction and dialogue within discrete communities, occurring informally or managed through leaders, promotes this form of emergence (Kozlowsi and Klein, 2000). Bottom-up emergence through compilation occurs through two complementary processes. The first, similar to the 'opportunity' dimension of the AMO framework (Appelbaum et al., 2000) entails exposure to alternative perspectives and offers the scope for individuals to apply their knowledge and skills in ways that suggest new options. The second involves reconciling these diverse insights, experiences and capabilities to form a collective whole (Kozlowski and Klein, 2000, through the use of autonomy, discretion, empowerment and so on, with these processes facilitated by those in leadership roles. According to our model, where this bottom-up process yields reflective innovation, compilation has occurred.

For compilation to occur, contingencies occur among contextual factors that influence particular patterns of emergence. For example, an organization might develop a strategic framework to enable the growth of empowered teams. HRM policies, reward system and management efforts would indicate their support for this activity, eventually resulting in stronger teams that self-regulate and achieve higher-level strategic goals (Kozlowsi, Chao and Nowakowski, 2010).

Several activities have the potential to foster compilation, given that efforts are made to reconcile the divergent perspectives that occur as a result. Communities of practice are an important mechanism for emergence (Brown and Duguid, 1991). The activity-based nature of knowing and expertise, where knowledge evolves through an on-going process of practice, application and experience (Swan et al., 1999) means that innovation is dependent on the active participation by employees in working and learning processes that focus on the role of changes in work process knowledge and practices.

Gupta et al. (2007), framing discussion of compilation in the light of enablers for innovation, describe the way in which networks evoke knowledge flow. Perhaps the only truly bottom-up compilation-oriented organizational forms are those where innovation is seen to require open, dynamic, virtual and networked spaces in which various systems of agents (individuals, groups, organizations and institutions) can voluntarily choose to collaborate (De Toni, Biotto and Battistella, 2012). For example, open innovation models based on web collaborations argue for a more virtual, co-created and collaborative innovation process, based on bottom-up and local interactions that operate 
without centralised control. Leadership is distributed and decentralised, and only exerted through an internal model of autonomy across the constellation of members at any point in time through a continual adaptation of values, rules, structures and behaviours, and relationships that are contemporaneously cooperative and competitive. Compilation then offers a way of understanding how bottom-up emergence can echo these dynamics. Based on these arguments, we propose our fourth and final proposition.

Research Proposition 4: Reflective innovative behaviours emerge through composition and compilation to engender reflective innovation

\section{DISCUSSION}

Although innovation is increasingly viewed as important in enabling organizations to survive in challenging global conditions, reorienting organizations to embrace this way of working has proved challenging. Insights from institutional theory suggest that institutional isomorphism constrains organizational endeavour, such that mimetic, coercive and normative pressures represent predominant influences rather than critically reflective thought (Di Maggio and Powell, 1983). A growing body of literature attests to the contribution that HRM has to make in eliciting innovation, with some scholars focusing their efforts on contexts where creative actions are explicitly required (Chang et al., 2014; Collins and Smith, 2006), and others arguing that all employees have the potential to foster innovation, given an environment that is conducive to this end (Shipton et al., 2006). Strategic HRM scholars have increasingly turned to multi-level perspectives in order to understand the effect of organizational contexts on individuals, including their creativity (e.g. Jiang et al., 2014). Although there is a growing understanding of the effect of particular HRM configurations on outcomes at the level of the organization as well as on employees, there is still no guiding framework that brings out what multi-level perspectives might mean where innovation is the focal point of interest. Mostly, SHRM has adopted a top-down perspective. In a few cases where bottom-up emergence receives attention, it is viewed primarily as a compositional process, in that outcomes at the collective level are indistinguishable in their elemental properties from those at a lower level of analysis.

In this paper, we make three main contributions. First, we inform literatures investigating HRM and innovation by bringing institutional theory centre stage. Although early institutional theorists argued that isomorphic pressures are immutable (Di Maggio and Powell, 1983) more recently scholars have proposed that organizations can establish a 
degree of hegemony through the agency of key players (e.g. Suddaby, 2014). Applying this principle with specific reference to HRM, Boon et al. (2013) demonstrated that while organizations vary in the space that they have to move beyond sector-specific requirements (their leeway) members may still take control through stepping away from dominant logics, actively critiquing and questioning underlying expectations and requirements and suggesting new directions. This process is enabled where members carefully position their ideas using rhetoric that reflects dominant institutional expectations (Rao and Giorgi, 2006). Scott (2004) suggests that actors shape organizational level factors including innovation through selective attention, collective interpretation, sense-making and so on. In our model, agency has an effect at two levels of analysis: in determining how the organization responds at a strategic level to institutional pressures; and in how it is encouraged and developed further down the organization.

Second, we propose a theoretical lens that spans levels of analysis. We argue that an organization's response to the institutional environment through its conditioning HR strategy (either control-based or entrepreneurial in orientation) influences employee innovative behaviours by highlighting what actions are important and valued. Depending on the signals they detect, employees may strive to perform actions that are legitimate and acceptable over and above those which are necessarily efficient and rational.

A multi-level framework is suggestive of two forms. The first, control-oriented HRM, is characterised by many indicators of best practice, such as performance appraisal, training, reward, job security, internal promotion and so on, but places less emphasis on measures designed to foster employee discretion, autonomy and voice. This is because organizations committed to this way of working are mainly concerned with enabling alignment and conformity with institutional pressures and are less willing to accept perspectives that may challenge this predominant orientation. For this reason, the degree of latitude extended to employees is restricted and employees are expected and encouraged to behave in ways that are legitimate and acceptable given isomorphic pressures. In these circumstances, employees are less likely to behave innovatively than might be the case where the institutional context has less bearing on their actions. It is not inconceivable, however, that individuals may exhibit innovative behaviours, which are skewed towards the dominant institutional logics that pervade across levels of analysis. Through bottom-up emergence that is isomorphic, or compositional in nature, any collective-level outcomes arising from these behaviours will be similarly oriented towards what is perceived to fit with the institutional context, rather than what is economically rational. Thus many innovations may be more fashion or fad oriented than based on critical reflection and detached observation. 
Another configuration, entrepreneurial HRM, fosters employee opportunity and scope for extending cognitive parameters and speaks to an area described recently as deserving of further research: how organizations can help employees to experience opportunity in the workplace, especially as this relates to variety, challenge and growth. Focusing on this quadrant builds on the work of contingency scholars in HRM such as Kang et al. (2007) and Chadwick and Dabu (2009) with two key points of difference. First, the primary purpose of this HRM configuration is to raise conscious awareness of the prevailing institutional framework and encourage critical reflection about what is acceptable and desirable with the intention of instigating economically viable innovation. Thus, HRM has the potential to foster reflective innovation to the extent that institutional pressures are consciously acknowledged. Secondly, entrepreneurial HRM gives rise to reflective innovation based on principles of compilation. This pattern of bottom-up emergence has not yet permeated literature in this area. Since compilation entails giving opportunities to employees to be exposed to new experiences and perspectives, and the reconciliation of those perspectives into a coherent whole, it has implications for HRM strategy.

Third, we provide insights into what compilation combined with composition might entail where innovation is concerned. Bottom-up emergence that takes place through composition is suggestive of elemental properties, employee beliefs, attitudes, values and so on, that converge through interaction and dialogue such that the emergent phenomena at a higher level of analysis, such as a climate for innovation (Scott and Bruce, 1994), is identical in form to its lower-level counterpart. In other words, employees hold more or less the same opinion about how supportive the organization is of innovation, the quality of knowledge-sharing, reward and recognition for creative endeavour, training conducive to this end and so on. The emergent phenomena is greater than the sum of the parts, and helps to bring about more incremental innovation as well as innovation that is oriented towards what is legitimate and acceptable. Compilation, the bringing together of diverse perspectives, is richer in the sense that the higher level emergent property it gives rise to is informed by insights that stand apart from the prevailing institutional paradigm. It requires careful acknowledgement and reconciliation of difference and is dependent on the capabilities of other members in tuning in to what others have to offer as well as leaders in orchestrating the various distinctive contributions that members bring.

Composition and compilation are not either or choices. Through compositional processes employees may interact in ways that open channels for the more challenging ideas likely to arise through compilation. The recognition and reward perceived for behaving innovatively (through composition) may extend to employees moving beyond their 
referent group to connect with other parties (through compilation), thereby challenging legitimacy aspirations. Optimum for innovation is a capacity to foster both forms of bottom-up emergence.

\section{Implications for practice}

Our work raises a number of important considerations for practitioners, especially about the need to understand and acknowledge the institutional parameters that influence HRM especially insofar as it releases innovation. It could be that isomorphic pressures (coercive, normative and mimetic), have a stronger bearing on practice than would ideally be the case, should economic rationality be brought to the fore. For example, coercive pressures such as those emanating from employment law or health and safety legislation, evoke fear and anxiety to the extent that the resulting HRM policy and practice is overly reactive and thereby unduly cumbersome. Normative pressures, concerning how the organization acknowledges, supports and extends its network of professional employees, may be unduly restrictive of employees elsewhere in the hierarchy, who may potentially perform as well or better than those traditionally employed in particular roles. Mimetic isomorphism is suggestive of innovation that is derived from adopting practices (such as semi-autonomous teams or empowered work practices) simply because comparator organizations are doing so, rather than as a result of critical reflection on whether such practices are apposite in a given context. These examples, which are observed in practice serve evidence of how control-based HRM may perpetuate patterns of working and behaviour constrain rather than open more productive options.

Those with responsibility for HRM, including specialists, line managers and senior management teams, should be aware that in order to foster reflective innovation it is necessary to have mechanisms in place to enable compilation as well as composition. This suggests creating opportunities for employees (and managers) to move beyond limited cognitive spheres into domains that enrich, open and extend their intellectual understanding so that they are better placed to contribute towards collective outcomes that add value rather than simply fulfil legitimacy aspirations. Opportunity, whilst under-researched (Jiang et al., 2013), not only provides scope for employees to apply their abilities and motivation; it also helps prime employees to question and critically explore new options. It is therefore central in any model of best practice HRM intended to promote innovation.

In order to engage in innovative behaviours that are critically reflective, it is important that managers offer latitude to employees so that they have a voice and influence, rather than simply being expected to conform, otherwise may perceive that certain actions are effectively out of bounds and be reluctant to give voice to their ideas for 
improving practice. Offering individual support, appreciation of unique attributes and working with teams to identify where these qualities promote emergence through compilation is important. This perspective gives credence to the role of leaders in bringing together divergent perspectives, and has implications for leadership development.

It could be that innovative behaviours are not perceived as desirable or necessary and indeed there are suggestions of a pro-innovation bias in the literature (Anderson et al., 2014). An institutional frame suggests though that an overly controlling managerial stance might perpetuate ways of working that are more sensitive to institutional parameters, coercive, normative or mimetic, than good ideas. Our model suggests that even given the same institutional parameters organizations have the potential to leverage differential outcomes, with reflective rather than conforming styles offering the more fruitful strategic options.

\section{Future research}

Several directions are proposed for future research. First, it is important to take into account whether creative/innovative behaviours are explicitly required, or whether the focal point of interest is behaviour that arises spontaneously, without being overtly expected. From there, we need to understand how compilation occurs, and what role opportunity, discretion and autonomy might play as a first stage in the process. This entails much deeper understanding into the process whereby diverse perspectives are reconciled, and the skill set and capabilities of leaders charged with enabling this type of emergence from the bottom up. Thirdly, it is important to understand and test empirically whether the configurations of HRM practices described here yield the multi-level effects that are expected. Fourthly, it would be valuable to understand the circumstances in which individuals exhibit agency and whether there is some moderating effect of agency in combination with opportunity that is conducive to this end.

Even so called 'best practice' HRM may not necessarily break through the isomorphic pressures that underpin organizational functioning, probably because although facets such as opportunity, participation, autonomy and so on are included in most measures it is not clear whether employees are experiencing such practices in a way that is conducive to adapting their behaviours such that more reflective and critical outcomes arise at the collective level

(Nishii et al., 2008). Following others, we argue that more research is urgently needed in this area (Jiang et al., 2013).

We suggest that one reason why inconsistent results are reported in extant work is that the institutional context and pressures towards conformity (Di Maggio and Powell, 1983) are not recognized. Leeway and agency are concepts that could add value to conceptualisations of HRM and innovation. How organizations deal with the isomorphic 
pressures that permeate levels of analysis to achieve innovation through the agency and proactive efforts of managers and employees? Do some individuals have a more influential effect on bottom-up emergence, whether composition or compilation in orientation, than others? Although HRM literature has started to look at the effect of institutional theory on organizational functioning more work is needed to understand whether and how organizations can achieve hegemony and what role HRM might play in this. Although we have argued that isomorphism explains how employee behaviours coalesce at collective levels, and what this means not just for an organization's propensity to innovate but also in terms of how legitimately or reflectively oriented the innovation is, empirical work is called for to test out these ideas and to assess what effect the context or sector might play.

\section{CONCLUSION}

In our model, which is underpinned by institutional theory, we focus on employee innovative behaviours that are beyond the requirements for the job. According to our model, HRM systems might elicit innovative behaviours that are reflective, in that they are driven by efforts to devise an outcome that is 'optimum' based on efficiency criteria, or alternatively suppress or even skew such actions. Through bottom-up emergence innovation can be either 'aligned' or 'reflective'. The former reflects an orientation by employees to behave in ways that are (perceived to be) legitimate and acceptable within an environment where conformity to institutional norms is paramount, and is driven by composition. The latter captures a propensity to challenge and question institutional norms and through building more open dialogue, arising from both composition and compilation. We hope that our multi-level model of HRM and innovation inspires future work to substantiate empirically these important, and we believe exciting, new directions.

\section{REFERENCES}

Alfes, K., Shantz, A., Truss, C. \& Soane, E. (2013). The link between perceived human resource management practices, engagement and employee behaviour: a moderated mediation model. The International Journal of Human Resource Management, 24: 330-351.

Anand, N., Gardner, H. \& Morris, T. (2007). Knowledge-based innovation: Emergence and embedding of new practice areas in management consulting firms, Academy of Management Journal, 50(2): 406-428.

Anderson, N. Potocnik, K. \& Zhou, J. (2014). Innovation and creativity in organizations: A state-of-the-science review, prospective commentary, and guiding framework. Journal of Management, 40(5): 1297-1333

Appelbaum, E., Bailey, T., Berg, P. \& Kalleberg, A. (2000). (eds.). Manufacturing advantage: why high performance work systems pay off. New York: Cornell University Press. 
Barney, J. (1991). Firm resources and sustainable competitive advantage. Journal of Management, 17(1): 99-120.

Bednall, T., Sanders, K. \& Runhaar, P. (2014). Stimulating informal learning activities through perceptions of performance appraisal quality and HRM system strength: A two-wave study. Academy of Management Learning and Education, 13: 45-61.

Benner, M. \& Tushman, M. (2003). Exploitation, exploration, and process management: The productivity dilemma revisited, Academy of Management Review 28(2): 238-56.

Beugelskdijk (2008). Strategic human resource practices and product innovation. Organization Studies, 29(6): 821847.

Boon, C., Paauwe, J., Boselie, P. \& Den Hartog, D. (2009). Institutional pressures and HRM: Developing institutional fit. Personnel Review, 38(5): 492-508.

Bowen, D. \& Ostroff, C. (2004). Understanding HRM-firm performance linkages: The role of 'strength' of the HRM system. Academy of Management Review, 29: 203-221.

Brown, J.S. and Duguid, P. (1991). Organizational learning and communities of practice: towards a unified view of working, learning and innovating. Organisation Science, 2(1): 40-57.

Cabello-Medina, C., Lopez-Cabrales, A. \&Valle-Cabrera, R. (2011). Leveraging the innovative performance of human capital through HRM and social capital in Spanish firms. The International Journal of Human Resource Management, 22 (4): 807-828.

Chadwick, C. \& Dabu, A. (2009). Human resources, human resource management and the competitive advantage of firms: Toward a more comprehensive model of causal linkages. Organisation Science, 20(1): 253- 272.

Chang, S., Jia, L., Takeuchi, R. \& Cai, Y. (2014). Do high-commitment work systems affect creativity? A multilevel combinational approach to employee creativity. Journal of Applied Psychology, 99(4): 665-680.

Carpenter, M., Li, M. \& Jiang, H. (2012). Social network research in organizational contexts: A systematic review of methodological issues and choice. Journal of Management, 38(4): 1328-1361.

Chen, C. \& Huang, J. (2009). Strategic human resource practices and innovation performance - The mediating role of knowledge management capacity. Journal of Business Research, 62: 104-114

Chesbrough, H. (2003). Open innovation: the new imperative for creating and profiting from technology. Boston: Harvard Business School Press.

Collins, C. \& Smith, K. (2006). Knowledge exchange and combination: The role of human resource practices in the performance of high-technology firms. Academy of Management Journal, 49: 544-560.

Delery, J. \& Shaw, J. (2001). The strategic management of people in work organizations: review, synthesis and extension. In Ferris, G.R. (Ed.), Research in Personnel and Human Resource Management. Stamford: JAI Press, 53101.

De Toni, A.F., Biotto, G. \& Battistella, C. (2012). Organizational design drivers to enable emergent creativity in webbased communities. The Learning Organization, 19: 335-349.

Di Maggio, P. and Powell, W. (1983). The iron cage revisited: Institutional isomorphism and collective rationality in organizational fields. American Sociological Review, 48(2): 147-160.

Dorenbosch, L., van Engen, M. \& Verhagen, M. (2005). On the job innovation: The impact of job design and Human Resource Management through production ownership. Creativity and Innovation Management, 14(2): 129-140.

Florén, H., Rundquist, J., Schuler, R.S. and Bondarouk, T. (2014). HRM and innovation: themes, contingencies and directions for future research, European Journal of International Management, 8(5): 570-577.

Fu, N., Flood, P., Bosak, J., Morris, T. \& O'Regan, P. (2015). How do high performance work systems influence organizational innovation in professional service firms? Employee Relations, 37(2): 209 -231.

Fulmer, C. \& Ostroff, C. (2015). Convergence and emergence in organizations: An integrative framework and review. Journal of Organizational Behavior, DOI: 10.1002/job.1987. 
Gupta, A., Tesluk, P. \& Taylor, S. (2007). Innovation at and across multiple levels of analysis. Organization Science, 18: 885-897.

Hodgkinson, G. \& Healey, M. (2008). Cognition in organizations. Annual Review of Psychology, 59: 387-417.

James, L., Demaree, R. \& Wolf, G. (1984). Estimating within-group interrater reliability with and without response bias. Journal of Applied Psychology, 69, 85 - 98.

Jensen, M., Johnson, B., Lorenz, E. and Lundvall, B.-Å. (2007). Forms of knowledge and modes of innovation. Research Policy, 36(5): 680-693.

Jiang, J. \& Liu, C. (2015). High performance work systems and organizational effectiveness: The mediating role of social capital. Human Resource Management Review, 25: 126-137.

Jiang, K., Chuang, C. \& Chiao, Y. (2014). Developing collective customer knowledge and service climate: The interaction between service-oriented high-performance work systems and service leadership. Journal of Applied Psychology, 1-18.

Jiang, K., Takeuchi, R. \& Lepak, D. (2013). Where do we go from here? New perspectives on the black box in strategic human resource management research. Journal of Management Studies, 50(8): 1448-1480.

Jimenez-Jimenez, D. and Sanz-Valle, R. (2008). Could HRM support organizational innovation? The International Journal of Human Resource Management, 19(7): 1208-1221.

Kang, S.-C., Morris, S. \& Snell, S. (2007). Relational archetypes, organizational learning, and value creation: Extending the human resource architecture. Academy of Management Review, 32: 236-256.

Kaše , R., Paauwe, J. \& Batistič, S. (2014). In the eyes of Janus: The intellectual structure of HRM-performance debate and its future prospects, Journal of Organizational Effectiveness: People and Performance, 1(1): 56-76.

Katou, A. and Budhwar, P. (2015). Human resource management and organisational productivity: A systems approach based empirical analysis. Journal of Organizational Effectiveness: People and Performance, 2(3): 244-266.

Kozlowski, S. \& Klein, K. (2000). A multilevel approach to theory and research in organizations: Contextual, temporal, and emergent processes. In K. Klein \& S. Kozlowski (Eds.), Multilevel theory, research and methods in organizations: Foundations, extensions, and new directions (pp. 3-90). San Francisco: Jossey-Bass.

Kozlowski, S., Chao, G. \& Nowakowski, J. (2010). Building an infrastructure for organizational learning: A multilevel approach. In S.W.J. Kozlowski \& E. Salas (Eds.), Learning, training and development in organizations. Mahwah, NJ: LEA.

Montag, T., Maertz, C. \& Baer, M. (2012). A critical analysis of the workplace creativity criterion space. Journal of Management, 38(4): 1362-1386.

McGrath, R. (2001). Exploratory learning, innovative capacity, and managerial oversight. Academy of Management Journal, 44(1): 118-131.

Nishii, L., Lepack, D. \& Schneider, B. (2008). Employee attributions of the 'why' of HR practices: Their effects of employee attitudes and behaviors, and customer satisfaction. Personnel Psychology, 61: 503- 545.

Paauwe, J. \& Boselie, P. (2003). Challenging 'strategic HRM' and the relevance of the institutional setting. Human Resource Management Journal, 13 (3): 56-70.

Patel, P., Messersmith, J. \& Lepak, D. (2013). Walking the tightrope: An assessment of the relationship between highperformance work systems and organizational ambidexterity. Academy of Management Journal, 56: 1420-1442.

Piaget, J. (1970). Science of education and the psychology of the child. New York: Orion Press.

Prieto, I., Perez-Santana, M. Sierra, C. (2010). Managing knowledge through human resource practices: empirical examination on the Spanish automotive industry. International Journal of Human Resource Management, 21(13): 2452- 2467.

Rao, H. and Giorgi, S. (2006). Code breaking: How entrepreneurs exploit cultural logics to generate institutional change. Research in Organizational Behaviour, 27: 269- 304.

Robeson, D., \& O'Connor, G. (2013) Boards of directors, innovation, and performance: An exploration at multiple 
levels, Journal of Product Innovation Management, 30(4): 608-625.

Sanders, K., Jorgensen, F., Van Rossenberg, Y., Wang, Y., Shipton, H., Li, X., Dysvic, A. \& Wong, S. (2015). HPWPs and innovative behaviour: Do HR strength and national culture matter? Academy of Management Conference, Vancouver.

Schuler, R. and Jackson, S. (1987). Linking competitive strategies with human resource management practices. Academy of Management Executive, 1, 3: 207- 219.

Scott, R. (2004). Institutions and organizations. Foundations for Organizational Science, London: Sage.

Scott, S. and Bruce, R. (1994). Determinants of innovative behavior: A path model of individual innovation in the workplace. Academy of Management Journal, 37: 580-607.

Shalley, C., Gilson, L. \& and Blum, T. (2009). Interactive Effects of Growth Need Strength, Work Context, and Job Complexity on Self-Reported Creative Performance. Academy of Management Journal, 52(3): 489-505.

Shipton, H., West, M., Dawson, J., Patterson, M. \& Birdi, K. (2006). Human resource management as a predictor of innovation. Human Resource Management Journal, 16(1): 3-27.

Suchman, M. (1995). Managing legitimacy: Strategic and institutional approaches. Academy of Management Review, 20 (3): 571-610.

Suddaby, R. (2014). Can institutional theory be critical? Journal of Management Inquiry, 24(1).

Sullivan, D. \& Ford, C. (2010). The alignment of measures and constructs in organizational research: The case of testing measurement models of creativity'. Journal of Business and Psychology, 25(3): 505-521.

Swan, J., Newell, S., Scarbrough, H. \& Hislop, D. (1999). Knowledge management and innovation: Networks and networking. Journal of Knowledge Management, 3(4): 262-275.

Takeuchi, R., Lepak, D. P., Wang, H., \& Takeuchi, K. (2007). An empirical examination of the mechanisms mediating between high-performance work systems and the performance of Japanese organizations. Journal of Applied Psychology, 92: 1069-1083.

Unsworth, K. \& Clegg, C. (2010). Why do employees undertake creative action? Journal of Occupational and Organizational Psychology, 83: 77-99.

West, M. and Farr, J. (1990). Innovation at work. In M. West and J. Farr (eds). Innovation and Creativity at Work, Chichester: Wiley.

Wolfe, R. (1994). Organizational innovation: Review, critique and suggested research directions. Journal of Management Studies, 31: 405- 429.

Yuan, F. \& Woodman, R. (2010). Innovative behavior in the workplace: The role of performance and image outcome expectations. Academy of Management Journal, 53(2): 323-342.

Zhao, Z.J. and Chadwick, C. (2014). What we will do versus what we can do: The relative effects of unit-level NPD motivation and capability. Strategic Management Journal, 35: 1867-1880. 